\title{
A Study of Acculturation and Adaptation of South Asians in Hong Kong
}

\author{
Kareen NingLianChing Tonsing, The University of Hong Kong, Hong \\ Kong
}

\begin{abstract}
The study of acculturation has been well-developed in western countries as evinced by the large volume of extensive literature available. However, in reviewing the literature on acculturation studies, it is evident that there is a dearth of information pertaining to the acculturation and adaptation experiences of South Asians in Hong Kong. Cross-cultural studies have increasingly been interested in investigating what happen to people who have grown up in one culture when they move to another cultural environment. Although there are a substantial numbers of South Asian immigrants in Hong Kong, very little is known about their experiences of acculturation and adaptation, the challenges and opportunities they encounter. To better understand their experiences, there is a a need to conduct a systematic and comprehensive study. This paper presents an outline and conceptual framework within which to investigate and examine the experiences of acculturation and adaptation of South Asian immigrants in Hong Kong.
\end{abstract}

Keywords: Acculturation, Psychological Adaptation, Sociocultural Adaptation, Social Support, South Asian, Hong Kong

\section{Introduction}

TMMIGRATION IS A worldwide phenomenon and people around the world have been migrating for various reasons, often due to economic reasons, social and political oppressions, and for family reunion. Whatever the reason, migration involved major changes in people's lives such as leaving their country, as well as changes that results from contact with the new culture. These changes can range from physical and environmental changes to change in values, attitudes, and behaviors. They may also encounter various adjustment problems due to language differences, cultural incompatibilities, and negative stereotypes. Berry (1997) employed the concept of acculturation to refer to these changes, which occurs at both the group and individual levels. Redfield, Linton and Herskovits (1936) defined acculturation as the changes that occur when individuals having different culture comes in direct and continuous contact, resulting in mutual influence on each other. Although this definition posit that both cultural groups experienced changes in certain aspects of their systems as a result of the contact, however, in most cases these changes tend to occur more on the part of the non-dominant group.

The study of acculturation has been well-developed in western countries, and there exist a large body of extensive literature regarding the acculturation of immigrants. In the context of Hong Kong, there is a dearth of information on the experiences of cultural adaptation among the South Asians. According to the 2006 Population Census, the ethnic minorities in Hong Kong constituted 5\% of the total population (Census and Statistics Department, 2007).

The International Journal of Interdisciplinary Social Sciences

Volume 5, Number 2, 2010, http://www.SocialSciences-Journal.com, ISSN 1833-1882

(C) Common Ground, Kareen NingLianChing Tonsing, All Rights Reserved, Permissions:

cg-support@commongroundpublishing.com 
It is therefore not surprising that most of the social services and resources were essentially geared toward serving the Chinese-speaking community (Second Report of the HKSAR, 2005). Although there was an increased influx of people migrating from South and South East Asian countries since the 1990s, not much is known about their adaptation process. The lack of empirical information on the acculturation experiences of South Asians in Hong Kong prevent us from fully understanding how they adapt to the new culture, the challenges and opportunities they encounter.

\section{The South Asians in Hong Kong}

The term 'South Asian' is a social construct that has been used to refer to people originating from countries such as India, Pakistan, Bangladesh, Nepal and Sri Lanka. Most of the South Asians who had come to the China coast in the early $18^{\text {th }}$ century were mainly from India, Pakistan, Bangladesh and Sri Lanka but in local parlance they were all referred to as 'Indian' (White, 1994, p. 1) regardless of where they are geographically from. The 'Indians' initially came to the China coast as British subjects and their involvement in trade and other vocations were part of the overall British operation in China and the Far East (Vaid, 1972). After the British gained control over India, it used its vast materials and human resources for the expansion of their empire, which in turn led to large-scale Indian emigration. According to Vaid (1972), there were four main reasons which attributed to the growth of South Asians in different parts of the British colonies during the early days. Firstly, the British recruited many 'Indians' into the military in India and then transported to different parts of the British Empire to work in the military and police forces. Secondly, many 'Indians' were also sent as indentured laborers to work in the Straits Settlements in Southeast Asia. Later, many of these laborers migrated to Hong Kong as sailors or traders. Thirdly, the British also recruited many educated 'Indians' to work as clerks in different parts of her colonies. Their aptitude for English enabled them to be recruited in clerical positions for the colonial government as well as private British trading firms, which in turn enhanced their socioeconomic position in the Colony. After the completion of their contract, many of these civil servants choose to settle in the Colony. Fourthly, there were the 'Indian' traders, merchants and money-lenders, who moved to different parts of the British Empire and made vast fortunes. In time, many of them also migrated to Hong Kong as traders and sailors.

The Nepalese, on the other hand, are relatively 'young' migrant as compared with their other South Asian counterparts. The settlement of the Nepalese in Hong Kong can be traced back to the recruitment of the Gurkha soldiers into the British armies in Hong Kong since 1948 (FEONA, 2000). By virtue of the Sino-British Joint Declaration of 1984, the Gurkha soldiers, their children and Nepalese civilians born in Hong Kong before January 1983 were granted the Right of Abode (ROA). It was only since the early and mid 1990s that the Nepalese began to exercise this right and came to settle in Hong Kong.

\section{Local Studies on South Asians in Hong Kong}

As noted, according to the 2006 Population by-Census the ethnic minorities in Hong Kong comprised of $5 \%$ (342 198) of the total population. Amongst these the largest subgroups are the Filipinos $(32.9 \%)$, followed by Indonesians $(25.7 \%)$. Given these large numbers, various researchers and scholars have focused their interest on investigating the lives of 
Filipina migrant workers (e.g. Constable, 1997, 2007; French, 1986), and to some extent on the Thai and Indonesian migrant workers (e.g. Hewison, 2003; Ng \& Lee, 2000; Sim, 2007). These studies have highlighted the plight and condition of migrant workers and the difficulties and constraints faced by them in Hong Kong.

A number of studies have also been conducted by various researchers on the Indian ${ }^{1}$ community in Hong Kong. Kwok and Narain's (2003) study of the Indian community in Hong Kong provided a comprehensive history about their diversities, and sociocultural lives. White (1994) also focused her study on the Indian communities in Hong Kong. She had explored and investigated the different regional and religious groups which further provided understand of the historical and cultural background of various Indian ethnic groups in Hong Kong. Plüss (2000) also tackled the issue of transnational identities of Hong Kong Indians in the second half of the $20^{\text {th }}$ century, focusing on the complexity of the phenomenon of Diaspora and the dynamism of the Indian communities in Hong Kong. All these studies have helped to bring out a better understanding of the historical background and cultural lives of the Indian communities as a distinctive group in Hong Kong, as well as in explaining their present situation.

Other local studies on ethnic minorities in Hong Kong have focused on various issues such as employment situations, racial discrimination, and education that have drawn the attention of scholars, concern groups and researchers (e.g. Ku, Chan, \& Sandhu, 2005; Chin, 2005; Loper, 2004; Yang Memorial Methodist Social Service, 2002). These studies have helped to raise awareness among scholars and social welfare organizations about issues such as racial discrimination, unequal education and employment opportunities. Racial discrimination has been considered by many researchers and stakeholders as an important barrier to social and labor market inclusion of ethnic minorities. Although findings from these studies have helped to shed light on their predicaments and the difficulties encountered in their everyday life situations, these studies are rather fragmented and do not provide a comprehensive understanding of their acculturation experiences, and the factors that affect or impede their overall adaptation. Systematic research on acculturation and adaptation of South Asians in Hong Kong therefore warrant further examination.

From the above literature review of local studies on South Asians in Hong Kong, it is evident that many researchers and scholars have focused to a large extent on the Indian communities in Hong Kong. Other local studies on ethnic minorities just focus on different issues that are related to education and employment opportunities, discrimination, etc. None of these studies focus specifically on the process of acculturation and adaptation. The present study therefore proposed to focus on two sub-groups of South Asians, that is, Pakistani and Nepalese in Hong Kong.

\section{Acculturation: Definition and Conceptualization}

The concept of acculturation has been employed in the social and behavioral sciences, especially among anthropologists and sociologists, for over a century (Olmedo, 1980). Although this concept has been initially used to describe and understand the process of modernization and westernization that many cultures and communities underwent during the $19^{\text {th }}$ and early $20^{\text {th }}$ century (Trimble, 2002), in recent times as international migration, economic globaliz-

\footnotetext{
${ }^{1}$ The term Indians here refer to people from India.
} 
ation and political conflicts have led to increased migration, the concept of acculturation has also become important to better understand the experiences of ethnic and cultural minorities.

One of the most widely cited definition of acculturation was the one proposed by Redfield, Linton, and Herskovits (1936, p. 149):

Acculturation comprehends those phenomena which results when groups of individuals having different cultures come into continuous first-hand contact with subsequent changes in the original culture patterns of either or both groups...

This definition implies that the process of acculturation involved change in both cultural groups due to the mutual influence of intercultural contact. In principle, acculturation is a neutral term that entails change in both cultural groups, but in practice, acculturation tend to induced greater change in the acculturating group than in the dominant group (Berry, 1990a). One reason for this could be the power advantage of dominant groups to impose cultural adaptation on immigrant groups. Within the realm of anthropological studies, the central focus of research has been placed on immigrants groups, while relatively little attention was paid to the pattern and process of change in the individual during the process of culturecontact.

From the social psychological approach, the study of acculturation tended to focused on the internal changes that individual experience during the process of acculturation. Graves (1967) had provided a distinction between group-level and individual-level of acculturation, and coined the term psychological acculturation to refer to individual-level of acculturation. Based on Redfield et al's (1936) definition of acculturation, Berry (1990b) had defined group-level acculturation as the process of change experience by the group as a result of contact with another culture, while at the individual-level it refer to the process of change the acculturating individual experienced due to contact with another culture and also due to being a participant in the general acculturative changes underway in their own culture. Thus, acculturation at the group-level may refer to the changes in the social structures and cultural practices of the group, while at the individual-level it refer to the change in the psychology of the acculturating individual.

\section{Theories of Acculturation Process}

In the acculturation literature, there are two predominant theoretical formulations of acculturation models: the unidimensional models (e.g. Gordon, 1964) and bidimensional models (e.g. Berry, 1980). The first model conceptualized acculturation as a linear process whereby change in cultural identity is seen to take place along a single continuum over the course of time. This concept posits that the change process is one-way, and the acculturating groups and individuals are thus expected to adopt the host culture at the cost of relinquishing their heritage culture. It also assumed that acculturation process is a zero-sum phenomenon (Cortes, 1994; Cuellar, Arnold \& Maldonado, 1995). In other words, it means acculturation process involved giving up one's cultural domain as individual moved towards another cultural domain, and there is no room for the two cultures to exist together within the individual. Over the years, the unidimensional models had been redefined by numerous researchers (e.g. Berry, 1980; Nesdale \& Mak, 2000; Sayegh \& Lasry, 1993) as they begin to acknowledge 
the bi-directional nature of acculturation and a more recent understanding of the construct suggest that acculturation is multifaceted and that true assimilation may never occur.

Theorists who adopt the bidimensional perspective placed emphasis on ethnic pluralism and conceptualized acculturation process as a two-dimensional framework. These two dimensions provide individuals the option to maintain or reject their heritage culture, while also participating and acquiring the values, attitudes and behaviors of the dominant culture. One of the most influential bidimensional models was the one developed by Berry (1974, 1980) which integrates the two dimensions as independent rather than on a single continuum in opposing direction. According to Berry's model, immigrant groups and individuals are confronted with two basic issues during the process of acculturation. The first issue involved asking to what extent they consider it of value to maintain their heritage culture and identity. The second issue involved asking whether they consider it of value to maintain contact and relations with other groups. When these two issues are considered simultaneously a conceptual framework is generated with four acculturation strategies or options available to individual and groups. These are: integration, assimilation, separation, and marginalization. It must be noted here that Berry treated these two issues as dichotomous variables for conceptualization purpose, and he does recognized the continuous nature of these variables, which can also be responded on a continuous scale ranging from positive to negative. Other terms such as attitudes, modes, styles, options, outcomes and preferences have also been used by different researchers and scholars to refer to the way individuals seek to engage in intercultural relations (Jasinskaja-Lahti, 2000).

From the point of view of non-dominant groups, integration strategy is characterized by strong identification and involvement with their cultural heritage and also with the dominant culture. Individuals who do not wish to maintain their cultural heritage, but prefer only to maintain contact and relations with host members are said to adopt the assimilation strategy. When individuals wish to maintain only their heritage culture while rejecting relations with the host members, it is defined as separation strategy. Marginalization characterizes those individuals who have little possibility or interest to maintain their heritage culture (which often is also due to enforce cultural loss), and maintaining relations with others (often due to discrimination or exclusion) (Berry, 2005).

Berry and colleagues have conducted several empirical studies among different acculturating groups in various countries to assess and validate these acculturation strategies (e.g. Berry, Kim, Power, Young \& Bujaki, 1989; Dona \& Berry, 2000; Krishnan \& Berry, 1992; Berry, Phinney, Sam \& Vedder, 2006). Most of these studies have shown support for integration mode to be the most adaptive, followed by separation or assimilation, while marginalization is the least favored mode. Integration mode has also been shown to be related to better outcome in terms of psychological well-being and sociocultural adaptation. Studies among ethnic minorities, and in particular among South Asians in western countries have also shown support for integration as the favored mode (Ghuman 1991, 1997, 1999; Robinson 2003). Integration mode can also enable immigrants to maintain aspects of their heritage culture, maintain relations with their own ethnic groups through which they can obtain support and resources, as well as maintain contact with the host group. 


\section{Adaptation}

Adaptations refer to the relatively stable changes that individual or group make in respond to external environmental demands (Berry, 1997, 2006). These adaptations can be short-term or extended over the longer term. The short-term adaptation usually occurs immediately during acculturation, and is sometimes negative and often disruptive in character. The literature on acculturation has shown that most acculturating individuals are usually able to achieve some long-term adaptation to the new cultural context after a period of time (Beiser, et al., 1988; Segall et al., 1990). Adaptation has also been commonly referred to as the level of 'fit' between the individual and the environment (Sam \& Berry, 2006). Thus, adaptation may be seen as the 'fit' through which a system is harmonized with the condition of its existence. However, this does not necessarily imply that individual or groups make adjustment by way of assimilation; sometimes it may also involved attempts to change the environment or to move away from it (i.e. by separation). Sometimes a 'fit' might be achieved between the acculturating individual and the new environment, while at other times, a 'fit' might not be achieved resulting from incompatible behavior between the two cultures, which can lead to varying degree of acculturative stress (Berry \& Sam, 1997).

In recent literature on psychological acculturation, Ward and colleagues (Searle \& Ward, 1990; Ward \& Kennedy, 1993a; Ward, 1996) have proposed and validated two distinct variables of adaptation, namely, psychological adaptation and sociocultural adaptation. Although empirically related, these two forms of adaptation are conceptually distinct and are predicted by different types of variables and the dimension of adjustment follow different patterns over time (Armes \& Ward, 1989; Searle \& Ward, 1990; Ward \& Kennedy, 1993b; Stone Feinstein \& Ward, 1990). For instance, it is observed that psychological problems tend to increase soon after contact and then gradually decrease over the course of time. Sociocultural adaptation on the other hand, tends to follow a linear improvement over time (Ward, 1996).

Psychological adaptation is based on affective responses, and refer to psychological and physical well-being (Schmitz, 1992), positive sense of personal and cultural identity, life satisfaction and good mental health (Sam \& Berry, 2006). It has been commonly assessed with measures of self-esteem (e.g. Grossman, Wirt, \& Davids, 1985) and psychological adjustment, including checklist to measure anxiety, depression and psychosomatic symptoms (Ryder, Alden \& Paulhus, 2000). Ward and colleagues have demonstrated that psychological adaptation is also affected by personality factors, life changes, and social support (Searle \& Ward, 1990; Stone-Feinstein \& Ward, 1990; Ward \& Kennedy, 1992).

Sociocultural adaptation is defined in terms of behavioral competence (Ward, 2001) and closely linked to the social skills paradigm popularized by Furnham and Bochner (1986) in their culture learning approach to cross-cultural transition. According to the culture learning perspective greater emphasis is placed on the role of learning culture-specific skills that are required in order to adapt to the new cultural environment. Sociocultural adaptation thus refers to individual's ability to manage or negotiate effective interactions in the new cultural milieu, especially in the areas of family life, work and school. It is usually measured in terms of individuals' difficulty to perform daily tasks such as making friends, participating in social activities, language skill, and ability to manage everyday-life issues (Berry \& Sam, 1997; Ward \& Rana-Deuba, 1999). Findings from empirical studies conducted by Ward and colleagues have shown that sociocultural adjustment is predicted by different sets of variables. 
For instance, length of residence in the new culture is seen to be one of the most important factors of successful sociocultural adjustment; others include resources such as higher education and income (Ataca, 1996), amount of contact with host nationals, and general cultural knowledge (Ward \& Kennedy, 1992; Ward \& Kennedy, 1993a). Thus, analysis of the factors that affect adaptation revealed that psychological adaptation is predicted by personality variables, life changing events and social support, while sociocultural adaptation is predicted by cultural knowledge, degree of contact, and intergroup attitudes.

\section{A Framework for the Study of Acculturation and Adaptation of South Asian in Hong Kong}

This section provides a framework for the study of acculturation experiences and adaptation of South Asians in Hong Kong. As discussed above, during cross-cultural transition, immigrants may experience various changes in their lives as they strived to established themselves and adjust in the new cultural environment. These changes entail making various adjustments such as learning new ways of interaction and communication, adapting to new social structures, establishing new goals, etc. The nature and extent to which these changes are absorbed or embraced by the acculturating individual will also depend to a large extent on the action of the individual as well as contextual factors. These include demographic factors such as age, gender, socioeconomic status, educational level and experiences of discrimination. Various studies and research on acculturation among immigrants have also found that these factors are seen to affect and moderate the relations between acculturation experiences and the outcome of acculturation. In addition, during the process of acculturation they may also face certain stresses that are related to their acculturation experiences which may be compounded with other experiences such as discrimination. All these factors may have a direct or indirect influence on their attitudes towards how they wish to live following contact, which in turn can affect their overall adaptation. Although the primary impetus for most immigrants to leave their country may be due to various reasons such as for economic improvement, family reunion, etc., the psychological factors also play an important role in determining how well they adapt in the new country. Therefore, it is also important to focus on the individual-level phenomenon which can serve to expound the means by which individuals achieve internal positive affect and psychological well-being across cultural contacts.

To understand and examine the acculturation process and the overall adaptation of South Asians in Hong Kong, the study will seek to explore their (i) acculturation experiences; (ii) acculturation strategies; and (iii) overall adaptation. Acculturation experiences will be conceptualized in terms of host language proficiency, social contact, experiences of discrimination and level of acculturative stress. Acculturation strategies will be based on Berry's fourfold model of acculturation strategies. Adaptation, as proposed by Ward and colleagues, will be examined in terms of psychological well-being and sociocultural competence in their everyday life situation. In addition, demographic variables and the role of social support will also be examined in greater detail. The role of social support is an important variable as various studies have shown that the presence of social support can help to buffer against acculturative stress. 


\section{Summary}

This paper provides a literature review on acculturation, its concept and definition, and a framework for the study of acculturation experiences among South Asians in Hong Kong. Although the study of acculturation has been well-developed and widely discussed in the western context, there are very limited empirical studies in this area in the context of Hong Kong. Systematic research on acculturation and adaptation of South Asians in Hong Kong can provide a better understanding of their experiences of the process, which in turn can help to provide implications for government policies and service providers. The study of acculturation is a complex area of research in cross-cultural studies that involve the process of more than one culture. The process of acculturation is also highly variable and depends on various factors. It must be noted here that not all individual will participate to the same degree in the acculturation process nor share the same goals. Therefore, in studies of acculturation it is also important to focus on the variation among individuals in the group that is undergoing acculturation.

\section{References}

Armes, K., \& Ward, C. (1989). Cross-cultural transitions and sojourner adjustment in Singapore. Journal of Social Psychology, 129(2), 273-275.

Ataca, B. (1996). Psychological and sociocultural adaptation of Turkish immigrants, Canadians and Turks. Paper presented at the XIII Congress of the International Association for Cross-cultural Psychology, Montreal, Canada. 1996, August.

Beiser, M., Wood, M., Barwick, C., Berry, J. W., daCosta, G., Milne, W., et al. (1988). After the door has been opened: Mental health issues affecting immigrants and refugees in Canada: Report of the Canadian Task Force on mental health issues affecting immigrants and refugees. Ottawa, Canada: Ministry of Supply and Services Canada, and Health and Welfare Canada.

Berry, J.W. (1974). Psychological aspects of cultural pluralism: Unity and identity reconsidered. In R. Brislin (Ed.). Topics in culture learning (pp. 17-22). Honolulu, Hawaii: East-West Culture Learning Institute.

Berry, J.W. (1980). Acculturation as varieties of adaptation. In A. Padilla (Ed.), Acculturation: Theory, models and some new findings (pp.9-25). Boulder, CO: Westview Press.

Berry, J. W. (1990a). Psychology of acculturation. In J. Berman (Ed.), Cross-cultural perspectives: Nebraska Symposium on Motivation Lincoln: University of Nebraska Press.

Berry, J. W. (1990b). Psychology of acculturation: Understanding individuals moving between cultures. In R. W. Brislin (Ed.), Applied cross-cultural psychology (pp. 232-253). Newbury Park, CA: Sage Publications.

Berry, J.W. (1997). Immigration, acculturation and adaptation. Applied Psychology: An International Review, 46(1), 5-68.

Berry, J. W. (2005). Acculturation: Living successfully in two cultures. International Journal of Intercultural Relations, 29, 697-712.

Berry, J. W. (2006). Stress perspectives on acculturation. In D.L. Sam, \& J.W. Berry (Eds.), The Cambridge handbook of acculturation psychology (pp. 43-57). Cambridge: Cambridge University Press.

Berry, J. W., Kim, U., Power, S., Young, M., \& Bujaki, M. (1989). Acculturation attitudes in plural societies. Applied Psychology: An International Review, 38, 185-206.

Berry, J.W., Phinney, J. S., Sam, D.L. \& Vedder, P. (Eds.). (2006). Immigrant youth in cultural transition: Acculturation, identity, and adaptation across national contexts. Mahwah, NJ: Lawrence Erlbaum 
Berry, J.W. \& Sam, D. (1997). Acculturation and adaptation. In J.W. Berry, M.H. Segall, \& C. Kagitcibasi (Eds.). Handbook of cross-cultural psychology, vol. 3, (pp. 291-326). Boston: Allyn and Bacon.

Census and Statistics Department (2007). Population by-Census: Thematic Report-Ethnic minorities. Hong Kong: Census and Statistics Department.

Chin, C.-H. I. (2005). Language rights and ethnic minorities in Hong Kong . . (Unpublished M.Phil thesis). Department of Chinese Translation and Linguistics, City University of Hong Kong, Hong Kong.

Constable, N. (1997). Maid to order in Hong Kong: Stories of Filipina workers. Ithaca, NY: Cornell University Press.

Constable, N. (2007). Maid to order in Hong Kong : Stories of migrant workers (2 ed.). Ithaca, London: Cornell University Press.

Cortes, D. E. (1994). Acculturation and its relevance to mental health. In R. G. Malgady \& O.Rodriguez (Eds.), Theoretical and conceptual issues in Hispanic mental health (pp. 54-67). Malabar, FL: Krieger.

Cuellar, I., Arnold, B., \& Maldonado, R. (1995). Acculturation rating scale for Mexican AmericansII: A revision of the original ARSMA scale. Hispanic Journal of Behavioral Sciences, 17(3), 275-304.

Dona, G., \& Berry, J. W. (2000). Refugee acculturation and re-acculturation. In A. Ager (Ed.), Refugees: Perspectives on the experience of forced migration (pp. 169-195). New York: Continuum.

FEONA. (2000). Equality for all races and sexes. Hong Kong: Far East Overseas Nepalese Association.

French, C. (1986). Filipina domestic workers in Hong Kong: A preliminary survey. Hong Kong: Centre for Hong Kong Studies, Chinese University of Hong Kong.

Furnham, A., \& Bochner, S. (1986). Culture shock: Psychological reactions to unfamiliar environments. London: Methuen.

Ghuman, P. A. S. (1991). Best or worst of two worlds: A study of Asian adolescents. Education Research, 33: 121-132.

Ghuman, P. A. S. (1997). Assimilation or integration? A study of Asian adolescents. Educational Review, 39, 23-35.

Ghuman, P. A. S. (1999). Asian adolescents in the West. Leicester: British Psychological Society.

Gordon, M. M. (1964). Assimilation in American Life. New York: Oxford University Press.

Graves, T. D. (1967). Psychological acculturation in a tri-ethnic community. Southwestern Journal of Anthropology, 23, 337-350.

Grossman, B., Wirt, T., \& Davids, A. (1985). Self-esteem, ethnic identity, and behavioral adjustment among Anglo and Chicano adolescents in West Texas. Journal of Adolescence, 8, 57-68.

Hewison, K. (2003). A preliminary analysis of Thai workers in Hong Kong: Survey results. Hong Kong: City University of Hong Kong, Southeast Asia Research Centre Working Paper No.44.

Jasinskaja-Lahti, I. (2000). Psychological acculturation and adaptation among Russian-speaking immigrant adolescents in Finland. Finland: Department of Social Psychology of the University of Helsinki.

Krishnan, A., \& Berry, J. W. (1992). Acculturative stress and acculturation attitudes among Indian immigrants to the United States. Psychology and Developing Societies, 4(2), 187-212.

Ku, H.B., Chan, K.W., \& Sandhu, K.K. (2005). Research report on the education of South Asian ethnic minority groups in Hong Kong. Hong Kong: Centre for Social Policy Studies, Department of Applied Social Sciences, the Hong Kong Polytechnic University; Unison Hong Kong.

Kwok, S. T., \& Narain, K. (2003). Co-prosperity in cross-culturalism: Indians in Hong Kong. Hong Kong: Chinese University Press.

Loper, K. (2004). Race and equality: A study of ethnic minorities in Hong Kong's education system: project report and analysis. Hong Kong: Centre for Comparative and Public Law, the University of Hong Kong. 
Nesdale, D., \& Mak, A. S. (2000). Immigrant acculturation attitudes and host country identification. Journal of Community \& Applied Social Psychology, 10(6), 483-495.

Ng, S.-H., \& Lee, G. (2000). Thai migrant workers in Hong Kong. In Supang Chantavanich et al (Ed.), Thai migrant workers in East and Southeast Asia: The prospects of Thailand's migration policy in the light of the Regional Economic Recession: Returnees to Thailand. Bangkok: Asia Research Centre for Migration.

Olmedo, E. L. (1980). Quantitative models of acculturation: An overview. In A. M. Padilla (Ed.), Acculturation: Theory, models and some new findings (pp. 27-45). Boulder, CO: Westview Press.

Plüss, C. (2000). Transnational identities: Hong Kong Indians. The International Scope Review, 24 (4), 1-19.

Redfield, R., Linton, R., \& Herskovits, M. (1936). Memorandum for the study of acculturation. American Anthropologist, 38, 149-152.

Robinson, L. (2003). The adaptation of Asian and African Caribbean second generation youth in Britain. Paper presented at the International Conference on Diversity in Organizations, Communities and Nations, Hawaii. 2003, 13-16 February.

Ryder, A. G., Alden, L. E., \& Paulhus, D. L. (2000). Is acculturation unidimensional or bidimensional? A head-to-head comparison in the prediction of personality, self-identity and adjustment. Journal of Personality and Social Psychology, 79, 49-65.

Sam, D. L., \& Berry, J. W. (2006). Introduction. In D. L.Sam \& J. W. Berry (Eds.), The Cambridge handbook of acculturation psychology (pp. 1-10). Cambridge: Cambridge University Press.

Sayegh, L., \& Lasry, J. C. (1993). Immigrants; adaptation in Canada: Assimilation, acculturation, and orthogonal cultural identification. Canadian psychology, 34, 98-109.

Schmitz, P. (1992). Acculturation styles and health. In S. Iwawaki, Y. Kashima \& K. Hung (Eds.), Innovations in cross-cultural psychology. Amsterdam: Swets \& Zeitlinger.

Searle, W., \& Ward, C. (1990). The Prediction of psychological and sociocultural adjustment during cross-cultural transitions. International Journal of Intercultural Relations, 14, 449-464.

Segall, M., Dasen, P., Berry, J. W., \& Poortinga, Y. (1990). Acculturation. In M. Segall (Ed.), Human Behavior in Global Perspective: An introduction to cross-cultural psychology (pp. 299-323). Boston: Allyn and Bacon.

Sim, A. S. C. (2007). Women in transition: Indonesian domestic workers in Hong Kong. M.Phil (Unpublished thesis), The University of Hong Kong, Hong Kong.

Stone-Feinstein, E., \& Ward, C. (1990). Loneliness and psychological adjustment of sojourners: New perspectives on culture shock. In D. M. Keats, D. Munro \& L. Mann (Eds.), Heterogeneity in cross-cultural psychology (pp. 537-547). Lisse, The Netherlands: Swets \& Zeitlinger.

Trimble, J.E. (2002). Introduction: Social change and acculturation. In K.Chun, P.B. Organista \& G. Marin (Eds.), Acculturation: Advances in theory, measurement, and applied research (pp.314). Washington DC: American Psychological Association.

Vaid, K. N. (1972). The overseas Indian community in Hong Kong. Hong Kong: Centre of Asian Studies, The University of Hong Kong.

Ward, C. (1996). Acculturation. In D. Landis \& R. S. Bhagat (Eds.), Handbook of intercultural training (2 Ed., pp. 124-147). Thousand Oaks, CA: Sage.

Ward, C. (2001). The ABCs of acculturation. In D. Matsumoto (Ed.), Handbook of culture and psychology (pp. 411-445). New York: Oxford University Press.

Ward, C., \& Kennedy, A. (1992). Locus of control, mood disturbance and social difficulty during cross-cultural transitions. International Journal of Intercultural Relations, 16, 175-194.

Ward, C., \& Kennedy, A. (1993a). Where's the 'culture' in cross-cultural transition: Comparative studies of sojourner adjustment. Journal of Cross-Cultural Psychology, 24(2), 221-249.

Ward, C. \& Kennedy, A. (1993b). Psychological and socio-cultural adjustment during cross-cultural transitions: A comparison of secondary students at home and abroad. International Journal of Psychology, 28, 129-147. 
Ward, C., \& Rana-Deuba, A. (1999). Acculturation and adaptation revisited. Journal of Cross-Cultural Psychology, 30 (4), 422-442.

White, B.-S. (1994). Turbans and traders: Hong Kong's Indian communities. Hong Kong: Oxford University Press.

Yang Memorial Methodist Social Service. (2002). A study on the outlets of the South Asian ethnic minority youth in Hong Kong. Hong Kong: Author.

\section{About the Author}

Kareen NingLianChing Tonsing

Kareen N. Tonsing is a registered social worker, and currently pursuing her doctorate degree at the University of Hong Kong. Her research interest lies in cross-cultural studies, social policy, acculturation and adaptation. Having worked with people from diverse backgrounds, Kareen is interested in studying cross-cultural relations, and to understand how immigrants adjust to living in a new country, the factors that hinder or impede in their adjustment process, and the challenges and opportunities they encounter in the process. Her present research focuses on the acculturation and adaptation of South Asians in Hong Kong. 
Copyright of International Journal of Interdisciplinary Social Sciences is the property of Common Ground Publishing and its content may not be copied or emailed to multiple sites or posted to a listserv without the copyright holder's express written permission. However, users may print, download, or email articles for individual use. 